\title{
The Effect of Low Dose-Rate Irradiation on the Microstructure of 304 Stainless Steel*
}

\author{
by
}
J. I. Cole and T. R. Allen
Argonne National Laboratory - West
Engineering Division
Idaho Falls, ID 83403-2528 USA

\begin{abstract}
The submitted manuscript has been created by the University of Chicago as Operator of Argonne National Laboratory ("Argonne") under Contract No. W-31-109-ENG-38 with the U.S. Department of Energy. The U.S. Government retains for itself, and others acting on its behalf, a paid-up, nonexclusive, irrevocable worldwide license in said article to reproduce, prepare derivative works, distribute copies to the public, and perform publicly and display publicly, by or on behalf of the Government.
\end{abstract}

Paper to be submitted to Materials Research Society November 30 - December 4, 1998

Boston, MA

*Work supported by the U.S. Department of Energy, Materials/Chemistry, Materials Characterization, under Contract W-31-109-ENG-38. 


\section{DISCLAIMER}

This report was prepared as an account of work sponsored by an agency of the United States Government. Neither the United States Government nor any agency thereof, nor any of their employees, make any warranty, express or implied, or assumes any legal liability or responsibility for the accuracy, completeness, or usefulness of any information, apparatus, product, or process disclosed, or represents that its use would not infringe privately owned rights. Reference herein to any specific commercial product, process, or service by trade name, trademark, manufacturer, or otherwise does not necessarily constitute or imply its endorsement, recommendation, or favoring by the United States Government or any agency thereof. The views and opinions of authors expressed herein do not necessarily state or reflect those of the United States Government or any agency thereof. 


\section{DISCLAIMER}

Portions of this document may be illegible in electronic image products. Images are produced from the best available original document. 


\title{
THE EFFECT OF LOW DOSE-RATE IRRADIATION ON THE MICROSTRUCTURE OF 304 STAINLESS STEEL
}

\author{
J. I. Cole and T. R. Allen, Argonne National Laboratory-West \\ PO Box 2528, Idaho Falls, ID 83403-2528
}

\section{ABSTRACT}

Changes in mechanical and corrosion properties caused by the development of radiationinduced microstructures have relevance to the aging and lifetime extension of light water reactors (LWR's). However, much of the current data related to microstructural development in irradiated metals are generated from studies carried out at much higher dose-rates than encountered in LWR's. An opportunity exists to study the influence of low dose-rate irradiation on microstructural development for a variety of structural and surveillance materials extracted from the experimental breeder reactor EBR-II. In this study, irradiated 304 stainless steel hexagonal "hex" duct material is examined in order to compare microstructures in the dose-rate range of $10^{-7}-10^{-9}$ $\mathrm{dpa} / \mathrm{sec}$. The samples, taken from the reflector locations in EBR-II, experienced a total dose between 10 and $12 \mathrm{dpa}$ at a temperature of $\sim 375^{\circ} \mathrm{C}$. Transmission electron microscopy (TEM) results reveal that there is a moderate dose-rate effect on microstructural development for samples irradiated in the range of $2 \times 10^{-8}$ to $4 \times 10^{-8} \mathrm{dpa} / \mathrm{sec}$, however a substantial dose rate-effect exists between dose-rates of $2 \times 10^{-8}$ and $1 \times 10^{-9} \mathrm{dpa} / \mathrm{sec}$ Transmission electron microscopy (TEM) results will detail the development of the microstructure in terms of radiation-induced cavities, dislocations, and precipitates.

\section{INTRODUCTION}

Severe embrittlement of reactor materials can occur due to microstructural changes induced by radiation damage. These changes have been well documented in the high flux/temperature regime associated with the peak flux regions of fast reactors. However, a similar level of understanding has not been achieved for the development of microstructures in light water reactor (LWR) environments where dose-rates are typically two orders of magnitude lower. Because of the long times necessary to obtain meaningful total doses at low dose-rate combined with the proprietary nature of much of this data, there is little data published in the open literature describing the effects of low dose-rate irradiation on austenitic stainless steels.

With the current shutdown and decommissioning of EBR-II, a variety of materials have become available for examining the effects of long-term radiation damage on reactor components covering a range of dose and dose-rates encompassing the 30 year operational life of the reactor. For low dose rate studies, 304 and 316 SS hex duct material from reflector subassemblies were exposed to dose-rates similar to those experienced in LWR environments $\left(10^{-7}-10^{-9} \mathrm{dpa} / \mathrm{sec}\right)$. The operational temperature of EBR-II was $\sim 370^{\circ} \mathrm{C}$, which is at the upper end of the temperature range expected for certain PWR components when gamma heating is considered.

The objective of the current study is to evaluate the microstructures of three 304 SS hex duct materials irradiated at low dose-rates $\left(\sim 10^{-7}-10^{-9} \mathrm{dpa} / \mathrm{sec}\right)$ in the reflector region of EBR-II. Transmission electron microscopy results will detail the development of cavity, precipitate and dislocation structures and these results will be related to dose-rate effects on microstructural evolution, embrittlement and swelling.

\section{EXPERIMENTAL}

Of the three hex duct samples examined, one was from a different lot (A) than the two others (B and $\mathrm{C}$ ). The main difference in composition between the two lots was that hex duct $\mathrm{A}$ had substantially higher Mo and slightly more $C$ (Table 1 ). The starting condition of the hex ducts was mill annealed, and they were irradiated at temperatures between -375 and $380^{\circ} \mathrm{C}$ at average dose-rates ranging from $2.0 \times 10^{-8}$ to $4.7 \times 10^{-8} \mathrm{dpa} / \mathrm{sec}$ to a total dose between $\sim 10$ and $12 \mathrm{dpa}$. 
Table 1 Composition of hex duct material

\begin{tabular}{|l|l|l|l|l|l|l|l|}
\hline Hex Duct & $\mathrm{Cr}$ & $\mathrm{Ni}$ & $\mathrm{Mn}$ & $\mathrm{Si}$ & $\mathrm{Mo}$ & $\mathrm{C}$ & $\mathrm{Fe}$ \\
\hline $\mathrm{A}$ & 18.5 & 9.7 & 1.02 & 0.39 & 0.12 & $1090 \mathrm{wppm}$ & Balance \\
\hline $\mathrm{B} \& \mathrm{C}$ & 18.6 & 9.1 & 0.80 & 0.46 & $<0.036$ & $892 \mathrm{wppm}$ & Balance \\
\hline
\end{tabular}

Table 2 Irradiation history

\begin{tabular}{|c|c|c|c|c|c|c|}
\hline $\begin{array}{l}\text { Hex } \\
\text { Duct }\end{array}$ & $\begin{array}{l}\text { Temperature } \\
\left({ }^{\circ} \mathrm{C}\right)\end{array}$ & $\begin{array}{l}\text { Reactor } \\
\text { Grid } \\
\text { Position }\end{array}$ & $\begin{array}{l}\text { Time in } \\
\text { Grid } \\
\text { Position } \\
\text { (MWD) }\end{array}$ & $\begin{array}{l}\text { Dose in grid } \\
\text { position(total) } \\
\text { (dpa) }\end{array}$ & $\begin{array}{l}\text { Dose-Rate } \\
\text { in Grid } \\
\text { Position } \\
\text { (dpa/sec) }\end{array}$ & \begin{tabular}{|l} 
Average \\
Dose Rate \\
$(\mathrm{dpa} / \mathrm{s})$
\end{tabular} \\
\hline $\bar{A}$ & 379 & $\begin{array}{l}8 \mathrm{~F} 4 \\
14 \mathrm{E} 10\end{array}$ & $\begin{array}{l}5951 \\
348584\end{array}$ & $\begin{array}{|ll|}2.4 & (10) \\
7.6 & \\
\end{array}$ & $\begin{array}{l}2.9 \times 10^{-7} \\
1.5 \times 10^{-8}\end{array}$ & $2.0 \times 10^{-8}$ \\
\hline$\overline{\mathrm{B}}$ & 378 & $10 \mathrm{C} 2$ & 187505 & $12.2(12.2)$ & $4.7 \times 10^{-8}$ & $4.7 \times 10^{-8}$ \\
\hline $\bar{C}$ & 375 & $\begin{array}{l}8 \mathrm{~A} 3 \\
16 \mathrm{~B} 9\end{array}$ & $\begin{array}{l}60165 \\
107495\end{array}$ & $\begin{array}{ll}10.3 & (10.6) \\
0.3 & \end{array}$ & $\begin{array}{l}1.2 \times 10^{-1} \\
2.0 \times 10^{-9}\end{array}$ & $4.6 \times 10^{-8}$ \\
\hline
\end{tabular}

However, each of the subassemblies underwent a different irradiation history. Samples A and C were moved during their irradiation lifetime thereby experiencing different dose-rates due to substantial flux gradients in the reactor. While sample A spent most of its irradiation lifetime at a dose-rate close to its average, sample $C$ spent the second portion of its irradiation lifetime at a doserate more than one order of magnitude lower than its average. Following removal from the reactor, circular discs $2 \mathrm{~cm}$ in diameter were punched from the hex ducts and ground to approximately 250 $\mu \mathrm{m}$ thick. TEM discs $3 \mathrm{~mm}$ in diameter were then punched from the discs and prepared as thin foils using a twin-jet electropolisher and a solution of $95 \%$ methanol/5\% perchloric acid. Analysis was carried out in the TEM operating at an accelerating voltage of $200 \mathrm{kV}$. Sample thickness for cavity density measurements was determined using convergent beam electron diffraction (CBED).

\section{RESULTS AND DISCUSSION}

Overall the microstructures contain a high density of dislocations, cavities and small precipitates. Differences in composition and irradiation history make the task of comparing dose rate effects between the samples difficult. However, some information can be gained by comparing the current results to higher dose-rate studies.

\section{CAVITIES AND SWELLING}

Images of intragranular cavity and precipitate structures in the three samples are shown in Figure 1 which was taken slightly underfocus in order to enhance contrast provided by Fresnel interference. The smallest spherical bubbles are likely He gas bubbles generated from the coalescence of transmutation-induced $\mathrm{He}$ atoms. The size of these bubbles is limited due to internal gas pressure[1]. Larger cavities, many of which are faceted, are voids generated from the bias-driven influx of vacancies to the bubbles. Formations and growth of voids is are the major contributor to bulk swelling.

Figure 2 shows cavity diameter histograms for the 3 hex ducts, while Table 3 summarizes the mean cavity diameter along with the volume density of the cavities. Both voids and bubbles were included in the measurements because there is no definitive way of isolating cavity types. 


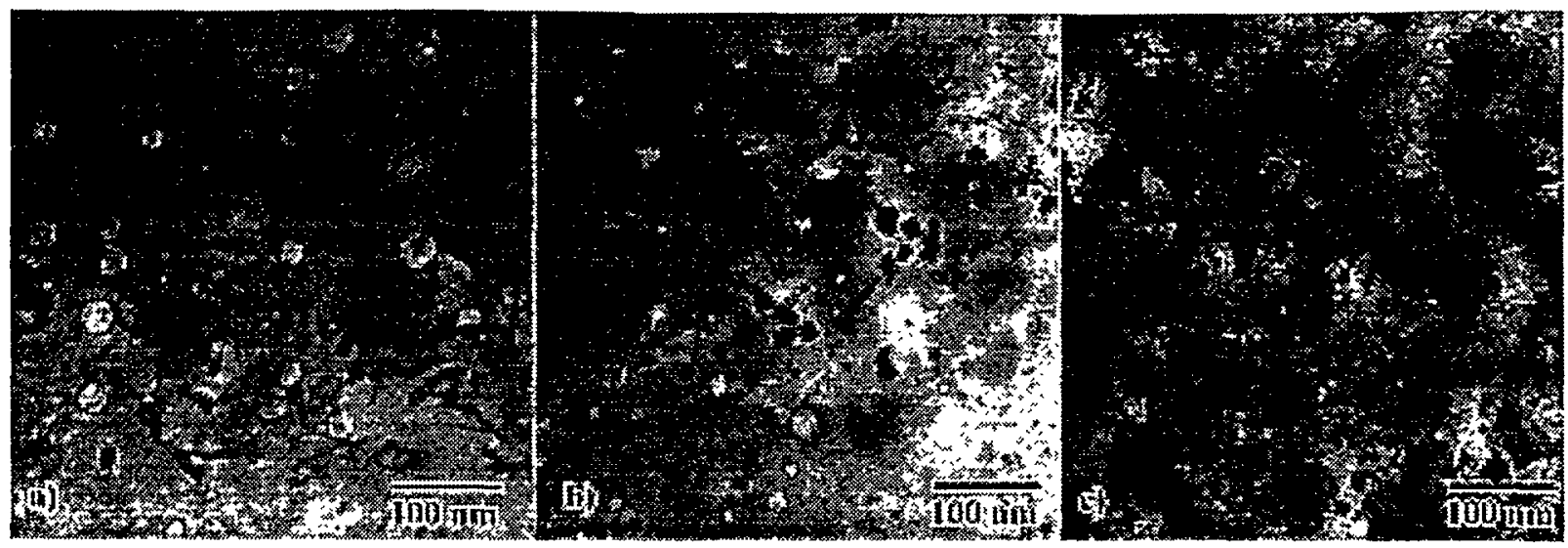

Figure $1 \mathrm{BF}$ images far from Bragg condition illustrating cavity and precipitate structure. Hex ducts a) A, b) B, and c) C.

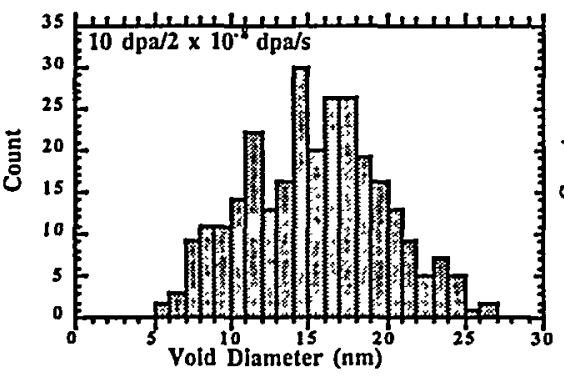

A

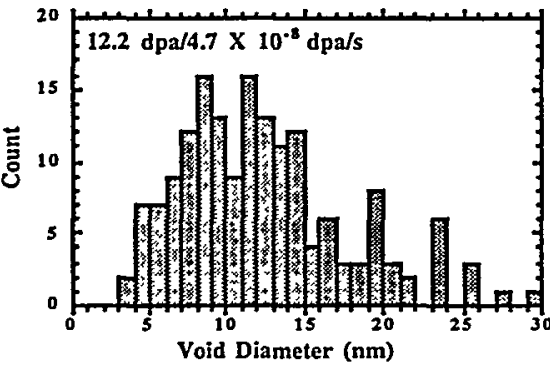

B

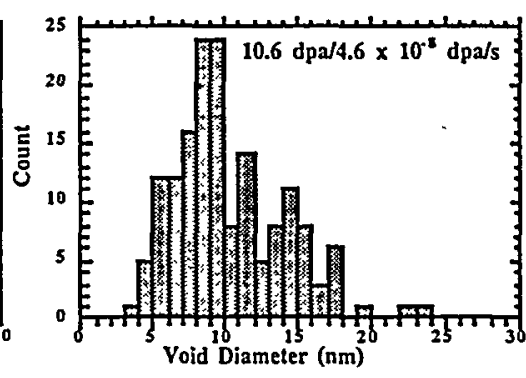

$\mathrm{C}$

Figure 2 Cavity size histograms for the three hex duct samples.

Table 3 Cavity size and density

\begin{tabular}{|l|l|l|l|l|l|}
\hline $\begin{array}{l}\text { Hex } \\
\text { Duct }\end{array}$ & $\begin{array}{l}\text { Temperature } \\
\left({ }^{\circ} \mathrm{C}\right)\end{array}$ & $\begin{array}{l}\text { Dose } \\
(\mathrm{dpa})\end{array}$ & $\begin{array}{l}\text { Average Dose- } \\
\text { Rate }(\mathrm{dpa} / \mathrm{sec})\end{array}$ & $\begin{array}{l}\text { Mean Cavity } \\
\text { Size }(\mathrm{nm})\end{array}$ & $\begin{array}{l}\text { Cavity Density } \\
\left(1 / \mathrm{m}^{3}\right)\end{array}$ \\
\hline $\mathrm{A}$ & 379 & 10 & $2.04 \times 10^{-8}$ & 15.65 & $5.19 \times 10^{21}$ \\
\hline $\mathrm{B}$ & 378 & 12.2 & $4.70 \times 10^{-8}$ & 11.46 & $1.34 \times 10^{21}$ \\
\hline $\mathrm{C}$ & 375 & 10.6 & $4.57 \times 10^{-8}$ & 9.37 & $4.47 \times 10^{20}$ \\
\hline
\end{tabular}

The table indicates that the sample which had the lower average dose-rate (A) contained a higher density of bubbles and voids than the two higher average dose-rate samples (B and $C$ ). In addition, in sample $A$ the mean size of the cavities and the size distribution was broader as a consequence of the presence of a large population of both He bubbles and voids.

An increased concentration of Mo in sample A may be responsible for the higher density of voids. Few studies have been done on the effect of Mo on void growth behavior, however studies on dislocation loop characteristics[2] suggest that Mo may trap Si which has been shown to 


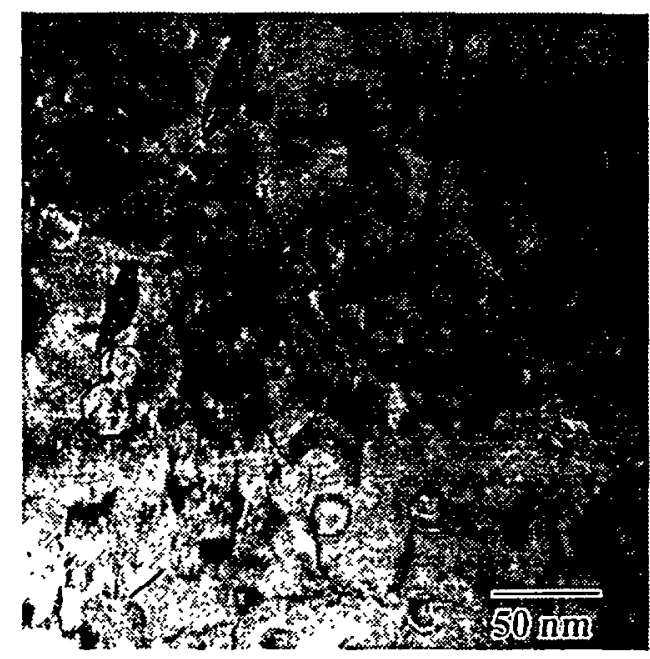

Figure $3 \mathrm{BF}$ image of dislocation structure in sample A showing presence of faulted dislocation loops and line dislocations. Voids can be seen associated with loops. enhance dislocation loop nucleation. A lower density of dislocations may then act to suppress He bubble nucleation thereby enhancing growth of voids.

The low density of cavities found in sample $\mathrm{C}$ is likely the consequence of the extended time spent at a substantially lower doserate. Although the total dose received during this time was only $0.3 \mathrm{dpa}$ out of the total of $10.6 \mathrm{dpa}$ received, the length of time spent at this dose-rate was nearly twice as long. Thermal effects may have lead to the dissolution of voids at the lower dose-rate. This result suggests that in this temperature range, a maximum swelling level will occur in the dose-rate range between $5 \times 10^{-8}$ and $1 \times 10^{-9} \mathrm{dpa} / \mathrm{sec}$.

At higher dose-rates, significant void swelling does not occur in austenitic stainless steels below $\sim 400^{\circ} \mathrm{C}$ as summarized by Maziasz [1], although, the majority of these studies have been done on alloys other than 304 SS. What has been observed in several studies is the formation

of high densities $\left(10^{22}\right.$ to $\left.10^{23} \mathrm{~m}^{-3}\right)$ of small $(1-2 \mathrm{~nm})$ He bubbles which can be stable up to fairly significant dose $[3,4,5]$. The He bubbles described in the higher dose-rate studies are much smaller than those seen in the present study and appear in greater density.

Bloom et al [6] characterized the microstructure of a 304 stainless steel irradiated at dose rates between $\sim 2 \times 10^{-6}$ and $1 \times 10^{-7} \mathrm{dpa} / \mathrm{s}$ in EBR-II to a range of doses. For samples irradiated at $370^{\circ} \mathrm{C}$, the average size and density of the cavities in the Bloom study were not dramatically different from those seen in hex ducts $A$ and $B$ of the current study. At $\sim 7 \mathrm{dpa}$, the majority of voids were in the 10 to $15 \mathrm{~nm}$ range with the void density being approximately $2 \times 10^{21} \mathrm{~m}^{-3}$. At $\sim 17 \mathrm{dpa}$, the density of voids had increased to $5 \times 10^{21} \mathrm{~m}^{-3}$ but the void size distribution did not change substantially. The size distribution of the voids in the Bloom study was cut off at the lower end (approximately $8 \mathrm{~nm}$ ), and no mention is made of smaller voids or bubbles, while in the current study there was a substantial density of cavities below $8 \mathrm{~nm}$. Hex duct A has similar cavity size density at $10 \mathrm{dpa}$ as the sample in the Bloom study at $17 \mathrm{dpa}$. Thus, a lower dose-rate translates into increased void density at a constant dose and subsequently enhanced swelling.

Cavity size and density results reveal that bulk swelling in the hex ducts is negligible at the dose levels studied. An estimate of swelling calculated from the volume displaced by the cavities reveals that hex duct $A$ undergoes the most swelling at approximately $1 \%$ with selling in hex ducts $\mathrm{B}$ and see being substantially lower than this. This low level of bulk swelling is an indication that none of the samples have reached the steady state swelling rate of approximately 1\% per dpa [7]. Prior studies on swelling behavior of 304 SS indicate that there is a minimum dose of approximately $10 \mathrm{dpa}$ before steady state swelling can occur which is independent of material and reactor variables [8]. The level of swelling found in the hex ducts is consistent with those findings. It has been suggested that swelling may be more substantial at the low dose-rates due to a temperature shift which may lead to a shortening of the transient regime prior to steady state void growth [9]. This would have substantial consequences for end of life dimensional stability in PWR components exposed to higher temperatures where there is a potential for void growth

\section{Dislocation Structure}

Dense populations of radiation-induced dislocations are also present in the hex ducts. Because of the overlapping strain fields of the dislocations, low magnification bright field images of the dislocation structure revealed little detail on the size and nature of the defects. A high magnification image taken near the foil edge of sample A (Figure 3) reveals the presence of faulted 

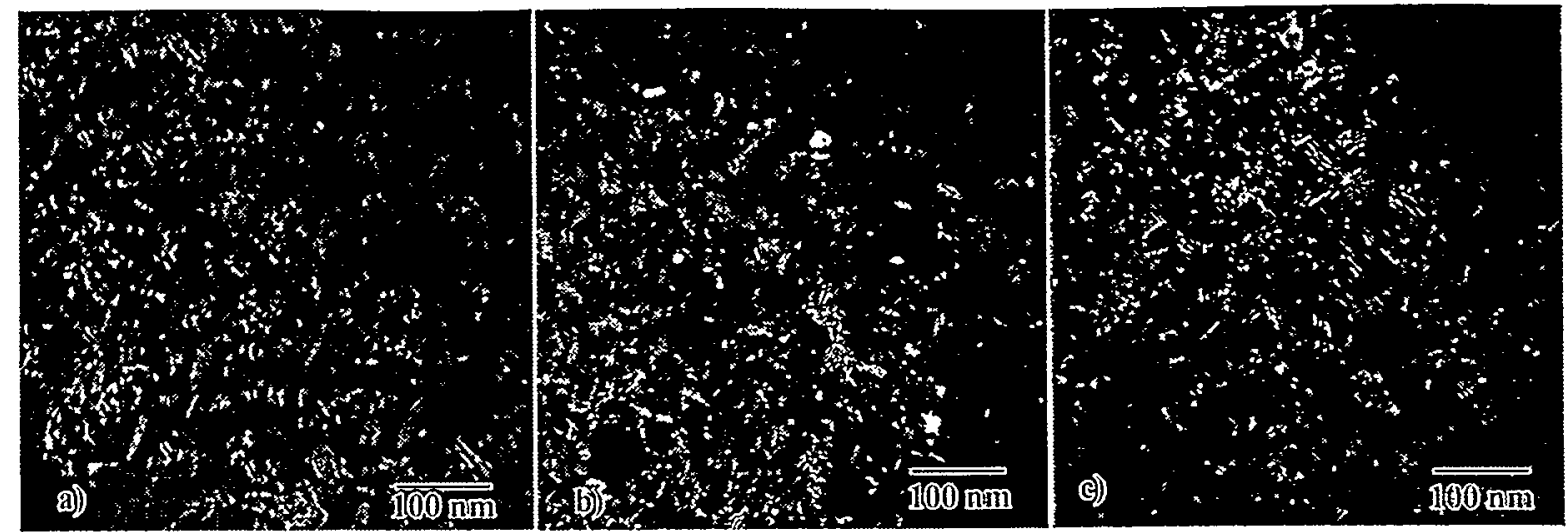

Figure 4 WBDF images of the dislocation structures in the hex duct samples. Hex ducts a) A, b) B, and c) C.

and unfaulted loops, line dislocations and other strain features which can't be uniquely identified. WBDF images of all three samples (Figure 4) reveal more clearly the distribution of loops and line dislocations. Small ( $<5 \mathrm{~nm}$ in diameter) dislocation loops frequently observed in lower temperature and dose irradiations[10] were not observed in these samples. Measurements indicate that the faulted loop diameters in all three hex duct samples were in the 30 to $60 \mathrm{~nm}$ range. Quantitative measurement of the individual defect densities was not performed due to the high density of strain contrast features. A substantial dose-rate effect on the dislocation structure among the 3 hex duct samples could not be identified.

There have been few studies detailing a dose-rate effect for the development of the dislocation structures. In comparing the present results to those of Bloom et al.[6], the dislocation structure in the hex ducts was considerably coarser (larger loops) than those observed by Bloom at the same temperature of $370^{\circ} \mathrm{C}$. This is consistent with a dose-rate effect that leads to a temperature shift in dislocation evolution behavior.

\section{Precipitate Structure}

Substantial precipitation can be seen in samples $\mathrm{B}$ and $\mathrm{C}$ while precipitation in sample $\mathrm{A}$ is less pronounced. In addition, substantial second phase precipitation on the grain boundaries of samples $B$ and $C$ were observed and few precipitates were seen on the boundaries of sample $C$. In sample $C$ many grain boundaries were severely etched by the electropolishing solution and others were completely obscured by precipitates, a strong indication that the sample is highly sensitized. Precipitates within the grains were frequently associated with voids and chemical analysis indicated they were rich in Si. A companion paper in these proceedings describes the chemical segregation behavior in these alloys including. [11]. Because of their small size attempts to identify the precipitates within the matrix were unsuccessful and extraction replicas of the samples will be prepared in the future to carry out this analysis. The unirradiated material showed no evidence of precipitation. In the work of Bloom et al on 304 SS irradiated at higher dose-rates, there was no mention of the kind of extensive precipitation observed in samples $B$ and $C$. This may also be attributable to a temperature shift due to the lower dose-rate.

\section{SUMMARY}

Results from this study provide some insight into the effect of dose-rate on the evolution of the microstructure in 304 SS. Comparisons with higher dose-rate studies indicate that at the dose levels examined there is a moderate dose-rate effect on void growth at in the dose-rate range of $\sim 1$ to $4 \times 10^{-8} \mathrm{dpa} / \mathrm{sec}$. However, dose rates below $1 \times 10^{-9} \mathrm{dpa} / \mathrm{sec}$ may actually reduce the amount of 
swelling at a temperature of $370^{\circ} \mathrm{C}$. Bulk swelling in the hex ducts was not significant, however the formation of voids at $10 \mathrm{dpa}$ indicates that swelling may be significant at higher doses. Dislocation loop size was greater in the hex ducts than in a similar study at a higher dose rate, indicating a dose-rate effect also exists for loop evolution. Additionally, significant precipitation in two of the Hex ducts suggests that dose-rate as well as variations in composition will affect precipitation behavior. It is clear from this study that dose-rate has an impact on all aspects of microstructural evolution, the understanding of which will be important for near end of life properties of PWR components.

\section{ACKNOWLEDGEMENTS}

The authors would like to acknowledge the assistance of M. E. Vaughn, J. P. Webb, E. L. Wood, Daryl Davis and the Staffs at the Hot Fuels Examination Facility and Analytical Laboratory at ANL-West. Additional thanks are extended to $\mathrm{K}$. N. Grimm and $\mathrm{K}$. A. Bunde for performing dose calculations and to $\mathrm{R}$. T. Jensen for performing the temperature calculations. This research was supported by the Division of Materials Sciences U.S. Department of Energy under contract DE-AC05-96OR22464 with Lockheed Martin Energy Research Corp.

\section{REFERENCES}

[1] Maziasz, J. Nucl. Mater. 205 (1993) 118

[2] H. Watanabe, A. Aoki, H. Murakami, T. Muroga and N. Yoshida, J. Nucl. Mater 155157 (1988) 815

[3] L. E. Thomas, Beeston, J. M., Journal of Nuclear Materials 107 (1982) 159

[4] P. J. Maziasz, in Fusion Reactor Materials Semiannual Progress Report, DOE/ER$01313 / 10$ (1991) 91.

[5] P. J. Maziasz and D. W. Braski, J. Nucl. Mater. 122\&123 (1984) 311

[6] E. E. Bloom, Stiegler, J.O. McHargue, C.J., Radiation Damage In Annealed Type 304 Stainless Steel in

[7] F. A. Garner, in Irradiation Performance of Cladding and Structural Steels in Liquid Metal Reactors in Materials Science and Technology: Nuclear Materials, B. R. T. Frost,

[8] D. L. Porter and F. A. Garner, in Effects of Radiation on Materials: Twelfth International Symposium, F. A. Garner and J. S. Perrin, eds. American Society for Testing and Materials, Philadelphia (1985) 212-220

[9] F. A. Garner, Greenwood, L. R, Harrod, D. L., Potential High Fluence Response of Pressure Vessel Internals Constructed From Austenitic Stainless Steels in Sixth International Symposium on Environmental Degradation of Materials in Nuclear Power Systems-Water Reactors, R. E. Gold, Simonen, E. P.,

[10] P. J. Maziasz and C. J. Mchargue, Int. Met. Rev. 32 (1987) 190

[11] T.A. Allen and J.I. Cole, in these proceedings. 